\title{
1
}

\section{It All Started in the Sixties: Movements for Change Across the Decades-A Personal Journey}

\author{
R. Eugene Rice \\ Association of American Colleges and Universities
}

A combination of memoir and social commentary, this chapter explores changes in higher education throughout five decades-1960s: utopian quest for learning communities; 1970s: faculty development movement; 1980s: focus on the academic workplace; 1990s: broadening the understanding of scholarship; and 2000s: new pathways and the engaged campus. This chapter provides a context for the careers and work of faculty, academic administrators, and faculty development specialists (both new and experienced) as well as for POD.

$\mathbb{1}_{\text {ment Network in Higher Education in its beginning years can trace our }}^{\text {any of us involved with the Professional and Organizational Develop- }}$ attraction to the 1960s. The civil rights movement inspired the press for institutional change with authentic moral confidence. The rapid expansion of higher education and the incredible growth during that decade sowed seeds of hope and provided genuine opportunities. Our horizons of expectation broadened. The free speech movement on the Berkeley campus was a fundamental challenge to academic authority. Students were demanding to be heard; the shift from teaching to learning was put in motion-the classroom would never be the same. The empowering-if naïve-words often attributed to Goethe were cited frequently and with conviction:

Whatever you do, or dream you can, begin it.

Boldness has genius, power, and magic in it.

Begin it now. 
During those heady days, I remember being inspired by Ralph Waldo Emerson's famous address "The American Scholar." Oliver Wendell Holmes came to regard the essay as "our intellectual Declaration of Independence." In that 1837 address Emerson raised the question I have pursued-or been pursued by-through most of my career: "What is the work of the scholar in a vibrant changing democracy?" It is a question that has its own intellectual tradition running from Emerson and Dewey to Richard Rorty and Cornel West. In the sixties this question and the larger issue, the relationship between education and democracy, took on new life. Dewey's ideas were resuscitated; he had taken the key elements of democracy-freedom and equality-and given them new meaning. On campuses in the 1960 s, freedom became not just freedom from (e.g., tyranny and oppression) but freedom to-freedom to grow and develop, freedom to learn, as individuals, as institutions, and as a country. It is the kind of freedom James Baldwin (1963) wrote about in The Fire Next Time, where he reflects on "our racial nightmare." There he speaks of the freedom and opportunity to "achieve our country and change the history of the world" (p. 119). Dewey also gave new meaning to equality: not just to be treated in the same way, but to celebrate our differences and learn from one another, to confront our differences and build a rich mosaic that strengthens our democracy and our humanity.

As we are frequently reminded, the utopian idealism of the sixties was countered by a dark side, the strong opposition to the civil rights movement and a ravaging war in Vietnam. The darkest days came in 1968 with the assassinations of the two public figures holding out the brightest promise for the future-Martin Luther King, Jr. and Robert F. Kennedy.

Higher education itself emerged from the yeasty period of the 1960 s with deep structural contradictions. Burton Clark (1987), one of the several talented sociologists devoted to understanding this period, writes of the "paradox of academic work." On the one hand is the structured hierarchy and competition leading to a higher education system that depends on research and is the "envy of the world" (p. 98), and on the other is a diverse and inclusively open system that requires that attention be paid to the quality of teaching and student learning. Clark's conclusion from his perch in a research university borders on the cynical: "This is the way the system operates." He warns that

Statesmen bent on major repairs soon find that their categorical imperatives, couched in the "musts" and "shoulds" of the rhetoric of reform, stumble over an inability to state "how" the incentives that decisively affect the behavior of institutions and professors might be changed. (p. 100) 
The movements for change that I propose to trace through the decades beginning with the 1960 s are ones in which I participated and that provided the scaffolding for my career. This is a personal journey shared, I am sure, by many who found themselves affiliated at one time or other with POD, AAHE (American Association for Higher Education), AAC\&U (American Association of Colleges and Universities), or other groups coming together to try to make a difference. Our conversations, I am confident, have been saturated with "musts" and "shoulds" (the rhetoric of reform) and have roots going back to the sixties. The movements shaping my life and work over the decades are these:

- 1960s: Utopian Quest for Learning Communities

- 1970s: Faculty Development Movement

- 1980s: Focus on the Academic Workplace

- 1990s: Broadening the Understanding of Scholarship

- 2000s: New Pathways and the Engaged Campus

I have been asked to be autobiographical. I do this with reluctance, not only because I run the risk of reflecting the self-absorption that is a special flaw of academic males in my age cohort, but because I am one of a group of senior faculty who were in fact especially privileged-structurally and demographically advantaged. The year I was born there were fewer babies born in the U.S. than at any other time in the century-born, as they would say in the business school, with a competitive advantage. The public high schools in Denver were unusually strong academically. When I graduated from college, major fellowships were available for those of us willing to consider college teaching as a career. Women were prohibited from applying for the fellowship (Danforth) that paid my way through to the Ph.D., and the number of minority candidates encouraged by their circumstances to apply was few. In the mid-sixties, when I was searching for my first faculty appointment, it was a buyer's market; colleges and universities were expanding in an unprecedented way. When I came up for tenure the process was not particularly onerous; in fact, tenure was often used to entice faculty with competitive offers to stay-a far cry from the present situation.

The professional advantage of my age cohort was a structural one, rooted in long-standing social injustices. This privileged experience often makes it difficult for senior faculty leaders to understand the very trying situations faced by today's early-career faculty or to envision a different kind of future for the professoriate. With this disclaimer I will proceed on my "personal journey" through the decades that frame my experience. 


\section{0s: Utopian Quest for Learning Communities}

\section{Beginning a Cluster College}

In their book The Perpetual Dream, Grant and Riesman (1978) caught the gist of what was so seductive about the experimental college in the 1960s. The winds of change erupting during the decade fanned the embers of utopian longing for community that had always been latent in American aspirations for higher education, and small experimental colleges began to appear across the landscape -365 by one count. California, as you might expect, provided especially volatile terrain.

In 1964, I began my teaching at Raymond College, the first of the cluster colleges at the University of the Pacific. It was intentionally patterned after Oxford and Cambridge: students graduated in three years, required liberal arts (one-third humanities, one-third social science, one-third math and natural science) with no majors, no grades (narrative evaluations), and High Table every Wednesday with the faculty on a raised platform in the Great Hall. The provost and a number of the faculty lived in the quad. Jerry Gaff (whose first book was on the cluster colleges) and I had offices across the hall from each another in one of the student residences. We were a close community_probably too close-and the "Hawthorne effect" was overwhelming.

Despite the utopian ethos, the experimental colleges of the 1960s were, by and large, counterrevolutionary. They came into being in opposition to the dominance of the large research-oriented universities-what Jencks and Riesman described in 1968 as The Academic Revolution. What they were opposed to was the rise of an academic hegemony dominated by an increasingly professionalized, research-oriented, discipline-driven, specialized faculty. The counter vision was a more intimate, democratic, studentoriented learning community. There was a Camelot quality to these places, and for a time wonderfully dynamic learning communities took shape. This dream informed my participation and that of many of my colleagues in the reform movements I want to trace across the following decades. It was the resilience of that vision-chastened and more nuanced-that later took me to another experiment, Antioch College, to try my hand at being dean of the faculty.

The vision of the learning community lives on explicitly in the much more pragmatic, diverse, and cost-effective learning communities that are now thriving across most states and sectors of higher education and have joined together to form a major national movement. It is no accident that this movement is rooted in The Evergreen State College experiment. 


\section{0s: Faculty Development Movement}

\section{: A Study of Danforth Fellows in Mid-Career}

In the 1970s, the focus of my work shifted to what became known as the faculty development movement and my membership on one of the early Core Committees that formed POD. In 1974, I went to the Danforth Foundation as a program officer and conducted a study of "Danforth Fellows in Mid-Career." The results were published as the lead article in the first volume of To Improve the Academy. That I ended up marrying one of the editors of that volume, Sandra Cheldelin, is probably a pivotal sign of the times and certainly the transformative event in the development of this faculty member-for which I will be forever grateful. I will refrain from discussing favoritism or objective peer review in this silver anniversary edition of the publication.

Maintaining the vitality of faculty had only recently emerged as a national concern. In fact, it was in 1974 that the influential booklet Faculty Development in a Time of Retrenchment (Group for Human Development in Higher Education) was published and launched what was to become a national movement. The academic job market had virtually shut down, particularly in liberal arts fields. At the annual AAHE meeting in 1974, Russell Edgerton convened foundation officers to discuss the issue; many-Lilly, Kellogg, Ford, and Danforth - had already funded several faculty-oriented projects. I remember debating, however, whether the concern for faculty development would last beyond the life of the grants.

Fortunately, there was a long-term research effort that was about to appear on the scene and make adult development a national preoccupation. Daniel Levinson's work on adult development had an enormous heuristic impact. His book, The Seasons in a Man's Life (Levinson, Darrow, Klein, Levinson, \& $\mathrm{McKee}, 1978$ ), was widely read and emulated. Gail Sheehy borrowed from it in writing Passages (1976) and launched a very lucrative career. What youth, the "identity crisis," and Erik Erikson were to the 1960s, the mid-life transition, generativity, mentoring, and Daniel Levinson became in the 1970s.

In spring 1975, and again in 1976, the Danforth Foundation invited 300 Danforth Fellowship recipients to a weeklong "Workshop on the Profession of Teaching." Daniel Levinson, William Perry, Herman Blake, and Robert Menges (a formative leader in the early days of POD) took the roles of master teachers. In preparation for the workshops, each fellow was sent the statement of personal and professional aspiration each had submitted when applying for this highly competitive national fellowship as seniors in college, some 10, 15, and even 20 years earlier. They were also sent an article by Levinson sketching out his theory of adult development and were asked to 
write a reflective essay on the relationship between their stated aspirations and what had actually happened in their lives over the intervening years. In reviewing the study, I was surprised at the number of themes that have persisted over time.

- The disappointment of so many in the absence of colleagueship among faculty. They had anticipated joining a community of scholars and failed to find it.

- The widespread perception of a disconnection between faculty work and the larger purposes of society.

- The sense of institutional drift in higher education.

As an English professor from a large state university in the Midwest put it:

My profession seems to me to flounder, to have lost faith in its old models and to be unable to find new ones. The result of floundering is a loss of cohesiveness and therefore a constant strain on intellect and emotion. Having lost the common ground that should nourish us, each individual has to invent his profession for himself.

Included in the study was a group of Graduate Fellowship for Women recipients (a program for women started belatedly in the 1960s after years of their being excluded from the competition). These women wrote of their struggles to integrate the personal and professional aspects of their lives as particularly difficult. In reviewing this study, it struck me that one of the major changes confronting faculty in the years since the 1960s is the dominance of the dual-career relationship. We have done very little to address the multitude of problems introduced by this change in the personal side of life. The work on these issues now being sponsored by the Sloan Foundation is especially important.

In my years of working on faculty issues, it was the time spent coping with developmental themes in faculty lives that was most satisfying. During this time, I began to teach a course titled "To Love and Work." I taught it to both traditional-age undergraduates and to what were referred to then as new adult learners. In addition, it was a central theme in my work with faculty. The attention to developmental issues needs to be reinvigorated and built into practice in the field of faculty development. Recent efforts with posttenure review and later-life career planning could provide the occasion. 


\section{0s: Focus on the Academic Workplace}

\section{Organizational Development}

In the 1980s, my work and interests shifted from personal and professional development to organizational development. This shift took place in both my local and more cosmopolitan work-in my teaching and research. This integration of the two was one way I coped with the perennial problem of inquisitive faculty who spread themselves too thin. I also moved from the experimental college at the University of the Pacific to the Department of Sociology and took on for a time the role of department chair.

The major study occupying my time in the mid-1980s dealt with the academic workplace in liberal arts institutions conducted for the Council of Independent Colleges (CIC). It gave me the opportunity to work closely with Ann Austin just as she was beginning her career. This study had a large quantitative research component but was also applied-a kind of action research. Ann did the hard quantitative work, and I organized a series of case studies of colleges that were identified in the study as having high faculty morale and satisfaction.

This work was intriguing to me not only because it allowed me to work with small, church-related colleges similar to the one from which I graduated (Pasadena College), but also because it involved working with other disciplines and professionals. We drew heavily on a creative career research project launched by schools of organization and management. The names of Schein, Driver, Van Mannen, Baylin, and Kolb will be familiar.

The organizational factors we identified as contributing to better faculty morale and satisfaction were

- A distinctive organizational culture

- Participatory leadership

- Organizational momentum

- Identification with the institution

Another key characteristic sustaining strong faculty morale and satisfaction emerging from the CIC study was "a broader definition of scholarship." These small colleges had found ways to recognize and reward the scholarly work of faculty that included but went well beyond specialized disciplinary research and publication. It was my preoccupation with this issue that later led to my going to the Carnegie Foundation for the Advancement of Teaching and participating with Ernest Boyer (1990) in the preparation of the Carnegie Report Scholarship Reconsidered: Priorities of the Professoriate. 
Another impetus that helped shape where I was going with the enlarged understanding of scholarship was an article I prepared in 1986 for my disciplinary journal, Teaching Sociology, titled "The Academic Profession in Transition: Toward a New Social Fiction." It was in writing that article, and through the deliberations of a wonderful seminar organized by the American Sociological Association to critique the offerings being considered for the journal, that the scaffolding for the ideas informing my work at Carnegie and later as director of AAHE's Forum on Faculty Roles and Rewards took form.

I am convinced that much about life is shaped by socially constructed fictions, patterns of meaning that cohere at a particular time and place. In preparing the article on the academic profession in transition, I took my lead from the American poet Wallace Stevens (1977):

The final belief is to believe in a fiction, which you know to be a fiction, there being nothing else. The exquisite truth is to know that it is a fiction and that you believe in it willingly. (p. 163)

Nowhere in the contemporary world do these socially constructed fictions have more power in our lives than in the professions. During that expansionist period in the 1960s in American higher education, a powerful fiction, an image of what it meant to be an academic professional, became firmly established among faculty. It was often reflected in institutional policies, shaped the graduate school experience of many of us, and-most insidiously-became solidly engrained in the way in which we thought about ourselves as professionals. This social fiction had a number of elements; some could be traced back to Oxford and Cambridge, others to Scotland, and most assuredly to the influence of the German universities, but during that heyday of affluence and expansion several came together to form what I tagged the "assumptive world of the academic professional." The controlling elements were these:

- Research is the central professional endeavor and the focus of academic life.

- Quality in the profession is maintained by peer review and professional autonomy.

- Knowledge is pursued for its own sake.

- The pursuit of knowledge is best organized by discipline.

- Reputations are established in national and international professional associations (not locally). 
- Professional rewards and mobility accrue to those who persistently accentuate their specializations.

- The distinctive task of the academic professional is the pursuit of cognitive truth.

This image of what it meant to be a scholar becomes normative for most faculty, dominating our thinking about our work, and specifically about what counts as scholarship.

In 1988, I went to the Carnegie Foundation for a two-year period that proved to be a significant turning point in my career. This generative transition was facilitated by the institution in which I had taught for 24 years and the faithfulness of a genuine mentor. Over the years, the University of the Pacific had consistently supported my more cosmopolitan career. When I would receive invitations to go to Washington, $D C$, or to work on various national projects, I was generously encouraged and would return, excited to be back. I loved teaching and working with undergraduates. The mentor was my undergraduate teacher Warren Bryan (Dick) Martin. When I was a graduate student, I met him crossing Harvard Square, and he invited me to join him in starting an experimental college in California. I accepted without ever visiting the campus for an interview. Dick was later the director of the Danforth Fellowship Program, inviting me there, and then senior scholar at the Carnegie Foundation. More important than the contacts he provided were the intellectual challenges and friendship over the years.

\section{0s: Broadening the Understanding of Scholarship}

\section{Making a Place for the New American Scholar}

In 1990, when I left the Carnegie Foundation for Antioch College, the manuscript calling for a broader conception of the scholarly work of faculty was titled "The New American Scholar." I had been intrigued with Antioch since my earliest involvement with the experimental college movement in the 1960 s and knew that it was envisioned as a "laboratory of democracy" which, since the inventive work of Arthur Morgan in the 1920s, had struggled to relate intellectual reflection in the liberal arts to the practical work of building a democratic society. The institutional mission was so congruent with my vision of what faculty ought to be doing that when I was approached about applying for the position of vice president and dean of the faculty I could not resist. 
I am glad I stayed as long as I did in a predominantly faculty role; it helped me better understand the changing nature of faculty work and increased my legitimacy when speaking about it. I am also grateful, however, for the experience as a chief academic officer. Some things are so complicated and "messy" that they can only be learned from experience. It also helped to have thoughtful colleagues such as Alan Guskin and Michael Bassis when working through the school's severe financial challenges and the contentiousness of faculty, students, and staff who take democratic aspirations seriously.

In 1994, I moved to Washington, DC, and to AAHE. No one could ask for a better platform from which to pursue the agenda I envisioned while at Carnegie- "Making a Place for the New American Scholar"- than to be director of the Forum on Faculty Roles and Rewards. Russ Edgerton, president of $A A H E$, and an imaginative group of major university provosts founded the forum with significant support from the Fund for the Improvement of Postsecondary Education. From the beginning there was a strategy in place for effecting change on local campuses. Colleges and universities were encouraged to send "teams" of faculty leaders and academic administrators to an annual conference to work on faculty-related issues central to the mission of the institution. Provosts knew that the initiative of their offices would not be enough, but that team members interacting with one another across administrative and faculty lines and with participants from other institutions struggling with similar issues, in the company of key resource people, could make a difference.

The first conference of which I had responsibility was titled "From 'My Work' to 'Our Work': Realigning Faculty Work with College and University Purposes." It took on the critical issue of an atomized faculty culture and the need to collaborate. In 1998, Peter Senge introduced the conference theme, "Faculty Work in Learning Organizations," and initiated a new way of thinking about faculty work. The year 2000 was the 10th anniversary of the publication of Scholarship Reconsidered. The new president of the Carnegie Foundation, Lee Shulman, was the lead speaker and the theme was "Scholarship Reconsidered Reconsidered." We had an attendance of 1,500, and an opportunity to take stock of what had happened since the publication of the report calling for a broader definition of scholarly work.

When Scholarship Reconsidered appeared in 1990, it immediately struck a responsive cord, becoming the bestselling publication in the history of the Carnegie Foundation. The primary agenda of the forum was driven by the issues raised in the Carnegie report about the nature of scholarly work, the changing faculty role, and criteria to be used in making decisions about tenure and promotion. Ernest Boyer's leadership was critical in drawing 
widespread attention to the report and its agenda. Few others had the national visibility, legitimacy, persuasiveness, and audacity required to effectively take on the task of redefining the meaning of scholarship and raising substantive questions about the relationship between faculty priorities and institutional missions. The report had an ongoing life- "legs" as they saybecause Russ Edgerton and the extraordinary staff of AAHE had enough foresight to develop an organizational initiative such as the forum to ensure that the ideas it sparked would not disappear. It was a pleasure to be at the confluence of these events.

The effort to broaden the definition of scholarship generated a large number of campus-based initiatives and a widespread national debate. Whether the effort will result in a movement that permanently changes the academic landscape, only time will tell. Under the leadership of Lee Schulman, Pat Hutchings, and Mary Huber, the Carnegie Foundation has put the scholarship of teaching and learning on the map, and Campus Compact has advanced the scholarship of engagement in creative ways. KerryAnn O'Meara and I (2005) have edited an inquiry aimed at assessing the impact of the work that has been done since the publication of the 1990 report. A series of impressive campus-based studies and a survey of the provosts of all four-year institutions support the claim that the broader definition of scholarship is being given serious consideration and is reflected in the tenure and promotion guidelines of the majority of colleges and universities. The study also demonstrated that the press for faculty research is being ratcheted up and prestige ranks continue to have an invidious influence. As Ernest Lynton put it, many institutions are continuing to strive to be what they are not, and "falling short of what they could be," guaranteed to be second rate.

\section{0s: New Pathways and the Engaged Campus}

The symmetry of my essay is breaking down as I move into the new century and a decade that is incomplete. However, there are two movements in which I have been involved that are gaining momentum: one, the development of new pathways in faculty work-which I find perilous-and the other, the engaged campus-which I find most promising.

One of the lines of work pursued by the Forum on Faculty Roles and Rewards was called "New Pathways: Academic Careers for the 21st Century." The project began by producing 14 studies of different dimensions of faculty work, ranging from tenure to part-time faculty. The New Pathways Working Papers generated widespread discussion-and some rather sharp controversy- 
about the future of academic work. The tenure discussions were particularly discordant. I was disappointed at the extent of the "turf" protection in the profession and the lack of openness. I came away with the sense that the fissures between the collegial culture of the faculty and the growing managerial culture were so divisive that unless we can cultivate a more collaborative culture-building on the strengths of both-higher education is going to suffer immensely.

The "Heeding New Voices" study in the New Pathways series (written with Mary Deane Sorcinelli and Ann Austin, 2000) provided insights into the perceptions of early-career faculty that were quite startling. In group interviews conducted across the country, junior faculty repeatedly reported a sense of being overwhelmed, of having-and this phrase was used frequently-an "overloaded plate." The older "assumptive world of the academic profession" I referred to earlier is still normative, but to that work are all the new reform agendas that have been added: the new demands on teaching and engagement, assessment, learning communities, service-learning, the list goes on. The question was raised time and again about whether the academic career we have encouraged to develop will attract the best of a new generation-is it viable?

For both individual and institutional reasons, new pathways are being developed with very little long-range planning. Full-time, nontenure-track appointments are proliferating with no one taking responsibility. Part-time faculty are added and dropped in an almost capricious way; they do the bulk of our teaching with very little faculty development support. Intentionally developed new pathways are much needed.

"Unbundling of the faculty role" is emerging as a key issue. Advances in instructional technology are driving this in settings such as the Open University in the UK and the for-profit institutions springing up in the U.S. Teams of experts-not all of whom are faculty-design online courses in a digital environment, making the unbundling not only possible but perhaps even inevitable. Learning communities involve student affairs personnel, librarians, and housing officers, as well as what we think of as traditional faculty, in the collaborative instructional processes. How faculty in these unbundled settings are rewarded represents a major challenge for the future. I am willing to argue that in the next ten years many faculty will have individualized contracts that are renegotiated every three to five years.

The idea of the "complete scholar" that I have contended for will be a possibility only over the length of one's professional career as one develops different aspects of one's scholarly self at different times. My concern for continuity, institutional memory, and a sense of the whole among faculty leaders 
is clearly losing ground at a time when-given the rapidity of change-it is most needed. I am confident, however, that in the future the sense of wholeness will be more collective and not as highly individualized as it is now. There is a lot of discussion of "new networks for learning" incorporating a wide variety of academic staff as well as off-campus personnel and resources working collaboratively. In my more optimistic moments, I see us moving toward new forms of reintegration, beyond the narrow specializations and organizational silos characterizing our work now. Doing this without losing the enormous benefits of our highly specialized world will be the challenge. Much of the work on new pathways will make them less hierarchical and more democratic. The big question is this: Will we have a two-tiered system with the nontenured, flexible, collaborative, inclusive appointments-more oriented toward teaching and community engagement-being on one level, and the more elite, tenured, research-oriented appointments being on another? There is some indication that we are already moving in this direction and that the second tier will be composed of more women and have a larger percentage of minorities.

The other movement that is rapidly gaining momentum is the engaged campus, with its emphasis on the scholarship of engagement. In February 2006, I attended a Wingspread Conference sponsored by the Johnson Foundation titled "Engagement in Higher Education: Building a Federation for Action." So many activities around civic and community engagement have blossomed lately that a national call for coordination and collaboration has gone out. The press for greater involvement in public life comes from two contradictory directions. On the one hand, there is the charge that the academy-and particularly the faculty-have become seriously disengaged, hustling for private gain with little concern for the public good. On the other hand, it is being argued that academic knowledge has never been more important to the life of the community, region, state, and global society. After all, the economies of the world are learning based and knowledge driven. Both sides acknowledge that the scholarship of engagement is not being adequately recognized and rewarded, that colleges and universities have failed to fully communicate what is being done to make the connection, and that the walls of our institutions need to be more permeable.

This movement calls for a fundamental change in our epistemological assumptions. No longer can we assume that knowledge is generated in academic settings and applied or exported; the generation and exchange of knowledge need to be multidirectional-a two-way street. Donald Schön and Lee Shulman have made the case for honoring the "wisdom of practice." 
If this movement is going to take hold, the relationship between cosmopolitan and local knowledge needs to be more fully explored; local knowledge is undervalued in the academy. Engaged, democratic pedagogy that is active, contextual, and value driven is getting a lot of attention and will be a key element in invigorating this movement. The enduring vitality of service-learning across the disciplines is making a major contribution to this development. Community-based research that has been around for years in various disciplines and professional pockets is now gaining visibility and is beginning to be coordinated nationally. The importance of making academic knowledge accessible can no longer be avoided. We have been irresponsible in the way we have used language. Public scholars are beginning to speak out and community partners are not only demanding to be heard, but to become full and legitimate participants in the pursuit and generation of knowledge.

The academy has never been good at relating theory and practice, and only with the advent of service-learning have we begun-on a larger scaleto generate a creative interchange between intellectual reflection and active practice. Only recently, in reading one of the Beat poets, Gary Snyder (1990), and his reflections on the power of meditative practice in the Buddhist tradition, have I come to a fuller appreciation of practice. He writes, "Practice is the path.... Practice puts you out there where the unknown happens, where you encounter surprise" (p. 153). We need more "surprise" of this sort in our colleges and universities and in our personal lives.

Allow me to close by quoting another poet whose lines I have probably cited in public much too often. These words are to my mind this culture's best commentary on the meaning of work and a fitting conclusion to these very personal reflections. They are the closing lines of Robert Frost's (1949) "Two Tramps in Mud Time":

Only where love and need are one, And the work is play for mortal stakes

Is the deed every really done

For Heaven and the future's sakes. (p. 359)

For those participating in the movements for change discussed here, work has not been play, although there have been some wonderful moments. I am confident, however, that important needs are being met by the work we have loved and it is making a difference. 


\section{References}

Baldwin, J. (1963). The fire next time. New York, NY: Modern Library.

Boyer, E. L. (1990). Scholarship reconsidered: Priorities of the professoriate. Princeton, N): Carnegie Foundation for the Advancement of Teaching.

Clark, B. R. (1987). The academic life: Small worlds, different worlds. Princeton, NJ: Carnegie Foundation for the Advancement of Teaching.

Frost, R. (1949). Complete poems of Robert Frost. New York, NY: Henry Holt \& Company.

Grant, G., \& Riesman, D. (1978). The perpetual dream: Reform and experiment in the American college. Chicago, IL: University of Chicago Press.

Group for Human Development in Higher Education. (1974). Faculty development in a time of retrenchment. New York, NY: Change Magazine Press.

Jencks, C., \& Riesman, D. (1968). The academic revolution. New York, NY: Doubleday.

Levinson, D. J., with Darrow, C. N., Klein, E. B., Levinson, M. H., \& McKee, B. (1978). The seasons of a man's life. New York, NY: Ballantine Books.

O'Meara, K. A., \& Rice, R. E. (2005). Faculty priorities reconsidered: Rewarding multiple forms of scholarship. San Francisco, CA: Jossey-Bass.

Rice, R. E. (1986, January). The academic profession in transition: Toward a new social fiction. Teaching Sociology, 14(1), 12-23.

Rice, R. E., Sorcinelli, M. D., \& Austin, A. E. (2000). Heeding new voices: Academic careers for a new generation. Washington, DC: American Association for Higher Education.

Sheehy, G. (1976). Passages: Predictable crises of adult life. New York, NY: Bantam Books.

Snyder, G. (1990). The practice of the wild. San Francisco, CA: North Point Press.

Stevens, W. (1977). Opus posthumous (S. F. Morse, Ed.). New York, NY: Alfred A. Knopf. 